\title{
REVISTA DE ADMINISTRAÇÃO EDUCACIONAL
}

ISSN -2359-1382

\section{dAEPEI}

GESTÃO DA FORMAÇÃO E ADMINISTRAÇÃO EDUCACIONAL: Uma experiência de estágio

\section{TRAINING MANAGEMENT AND EDUCATIONAL ADMINISTRATION: an internship experience}

Viviana Silva Ferreira ${ }^{1}$

\begin{abstract}
Resumo
Este artigo pretende apresentar uma experiência de estágio, realizada no Serviço de Formação Profissional de Águeda (Portugal) e no Centro Qualifica do mesmo, constituinte do Instituto de Emprego e Formação Profissional. Este estágio concretizou-se no âmbito do Mestrado em Gestão da Formação e Administração Educacional, da Faculdade de Psicologia e de Ciências da Educação da Universidade de Coimbra, para obtenção do grau de mestre na área de Organização e Gestão da Formação. O objetivo principal deste artigo é dar a conhecer as funções que um futuro profissional nesta área pode desempenhar em serviços de formação profissional como este.
\end{abstract}

Palavras-Chave: Centro Qualifica; Formação Profissional; Mestrado em Gestão da Formação e Administração Educacional; Universidade de Coimbra; IEFP.

\begin{abstract}
This article intends to present an internship experience, held in the Professional Training Service of Águeda (Portugal) and in their Qualifica Center, part of the Institute of Employment and Professional Training. This internship took place within the scope of the Master's in Management of Education and Educational Administration, at Faculty of Psychology and Educational Sciences of the University of Coimbra, to obtain a master's degree in Organization and Management of Training. The main objective of this article is to present the functions that a future professional in this area can perform in Training Services like this one.
\end{abstract}

Keywords: Qualifica Center; Professional Training; Master's in Management of Education and Educational Administration, University of Coimbra; IEFP.

\section{Introdução}

Este artigo apresenta a experiência de estágio concretizada no âmbito do Mestrado em Gestão da Formação e Administração Educacional (MGFAE), da Faculdade de Psicologia e

1 Mestre em Gestão da Formação e Administração Educacional pela Faculdade de Psicologia e de Ciências da Educação da Universidade de Coimbra (FPCEUC). Aveiro, Portugal. E-mail: vferreira2093@gmail.com 


\section{REVISTA DE ADMINISTRAÇÃO EDUCACIONAL}

ISSN -2359-1382

\section{dAEPEI}

de Ciências da Educação da Universidade de Coimbra, Portugal (FPCEUC). O objetivo principal deste artigo é dar a conhecer funções que podem ser desempenhadas por um profissional nesta área, em locais que desenvolvem formação profissional financiada pelo Governo Português.

O MGFAE conferia o grau de mestre nas áreas de especialização de Organização e Gestão da Formação e de Organizações Educativas e Gestão Escolar a quem obtivesse aprovação nas unidades do plano curricular e na defesa pública de dissertação ou de relatório de estágio, que foi a minha escolha (FPCEUC, 2015).

No início do ano letivo 2018/2019, o MGFAE mudou de nome, sendo designado Mestrado em Administração Educacional, perdeu as áreas de especialização e alterou o seu plano curricular. No entanto, ainda é utilizado o Regulamento do MGFAE para o regulamentar.

Relativamente ao estágio, que deve ter a duração mínima de 960 horas (FPCEUC, 2016), pretende que o estagiário se envolva num conjunto de atividades acordadas no Plano de Estágio, as analise, avalie e perceba como funcionam, e planifique eventuais intervenções, de sua iniciativa, que contribuam para o melhoramento dos serviços.

O local de estágio escolhido, foi o Serviço de Formação Profissional de Águeda (SFPA), que integra o Centro de Emprego e Formação Profissional de Águeda, unidade orgânica do Instituto do Emprego e da Formação Profissional, Instituto Público (IEFP). Este estágio iniciou em setembro de 2017 e terminou em maio de 2018, culminando na entrega do relatório de estágio e defesa do mesmo, em julho de 2018.

\section{O Instituto do Emprego e da Formação Profissional, IEFP.}

O IEFP é, segundo o Decreto-Lei n. ${ }^{\circ}$ 143/2012 de 11 de julho (PORTUGAL, 2012), um instituto público de regime especial, integrado na administração indireta do Estado, dotado de autonomia administrativa, financeira e património próprio e seguindo atribuições do Ministério da Economia e do Emprego..

Surgiu em 1970, constituído através do Decreto-Lei n. o $^{519-A 2 / 79}$ de 29 de dezembro, com o objetivo de integrar num único organismo a execução das políticas de emprego e formação profissional (PORTUGAL, 1979). 


\section{REVISTA DE ADMINISTRAÇÃO EDUCACIONAL}

ISSN -2359-1382

\section{dAEPEI}

Em 2019, conta com 5 Delegações Regionais: Delegação Regional do Norte, Delegação Regional do Centro, Delegação Regional de Lisboa e Vale do Tejo, Delegação Regional de Alentejo e Delegação Regional do Algarve.

Através dos serviços de emprego e formação profissional, tenta alcançar os seus valores, atribuições, visão e missão, que se destaca sendo a de "promover a criação e a qualidade do emprego e combater o desemprego, através da execução de políticas ativas de emprego, nomeadamente de formação profissional” (PORTUGAL, 2012, p. 3604).

Relativamente à vasta oferta formativa que apresenta, permite a obtenção de níveis de formação e de qualificação referenciados no Quadro Nacional de Qualificações.

A formação profissional pode ser procurada por qualquer pessoa e encontra-se disponível em empresas privadas de formação profissional certificadas pela Direção-Geral do Emprego e das Relações do Trabalho (DGERT), e através das Delegações do IEFP. Estas têm ao seu dispor em 2019, 30 Centros de Emprego e Formação Profissional, 23 Centros de Emprego e 1 Centro de Formação e Reabilitação Profissional, contando com o apoio de uma rede de Centros de Formação Profissional de Gestão Participada e mais de 300 Centros Qualifica (IEFP, 2018).

No contexto deste estágio, apresenta-se a Delegação Regional Centro visto o SFPA pertencer à Região Centro de Portugal. Esta delegação situa-se em Coimbra e compreende, segundo a Portaria n. ${ }^{\circ}$ 319/2012 de 12 de outubro, os Centros de Emprego e Formação Profissional de Águeda, Aveiro, Castelo Branco, Coimbra, Guarda, Leiria, Pinhal Interior Norte e Viseu, e os Centros de Emprego da Covilhã, do Dão - Lafões e da Figueira da Foz (PORTUGAL, 2012).

\section{O Serviço de Formação Profissional de Águeda, SFPA}

O SFPA (vd. Figura 1), juntamente com o Serviço de Emprego, integra o Centro de Emprego e Formação Profissional de Águeda, que inclui um Centro Qualifica desde março de 2017. 


\section{REVISTA DE ADMINISTRAÇÃO EDUCACIONAL}

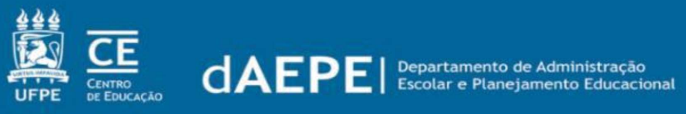

ISSN -2359-1382

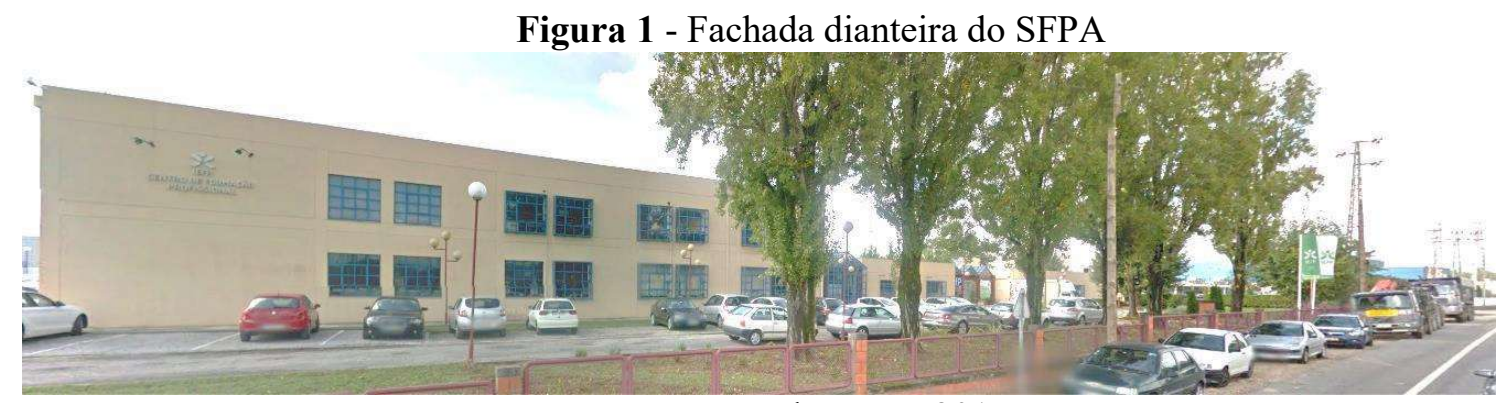

Fonte: Google Maps, 2017.

O Centro de Emprego e Formação Profissional de Águeda (CEFPA) abriu a 12 de setembro de 1988 e foi inaugurado oficialmente a 12 de outubro do mesmo ano (CEFPA, 2013). Este Centro localiza-se na sub-região do Baixo Vouga, no concelho de Águeda, distrito de Aveiro (vd. Figura 2) e abrange na sua área de atuação o próprio concelho e os concelhos de Anadia, Oliveira do Bairro, Albergaria-a-Velha e Sever do Vouga.

Figura 2 - Concelho de Águeda no mapa nacional e distrital.

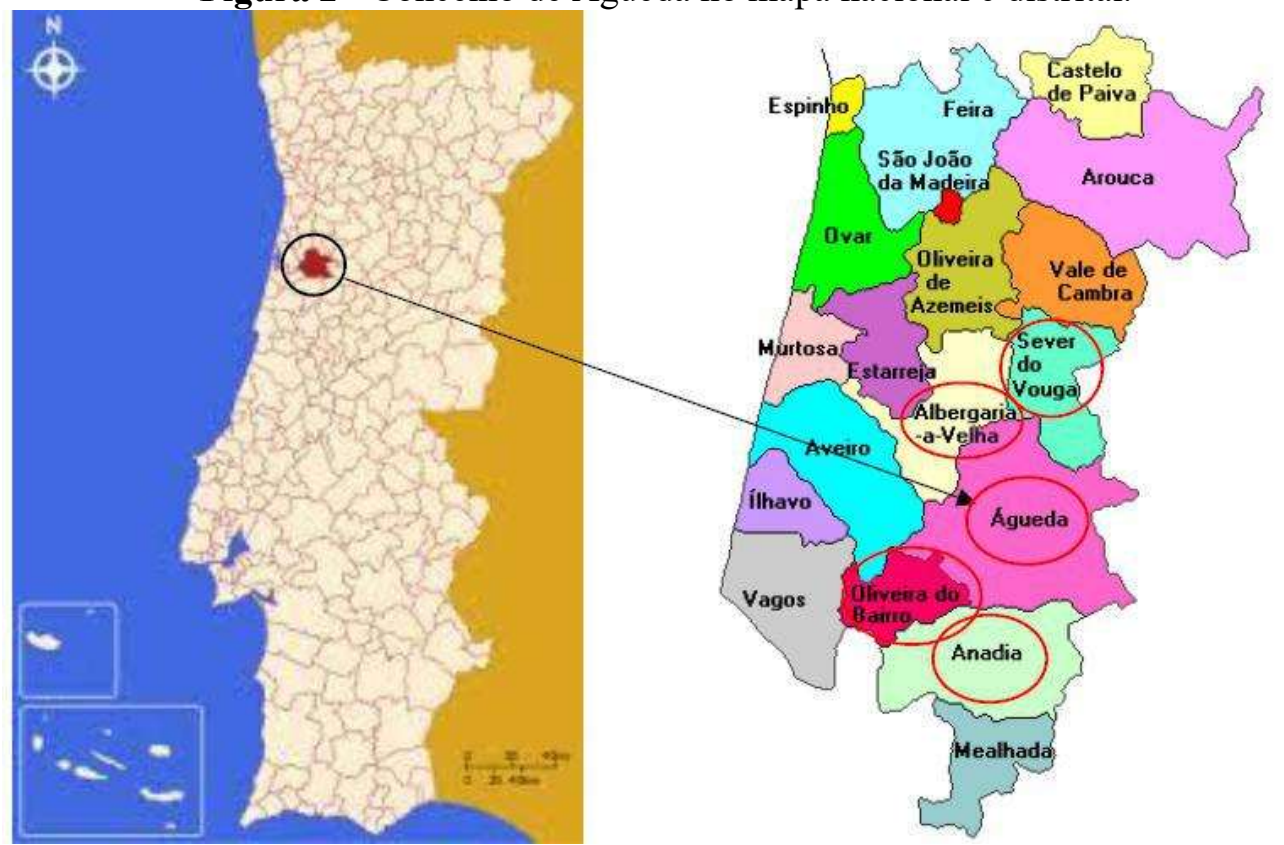

Fonte: Adaptado de VISITAR PORTUGAL, 2017 e PORTUGAL IN OUT, 2016.

O SFPA ao abranger estes concelhos compreende uma população residente de 133.882 habitantes (PORDATA, 2018) dos quais 3.339 são desempregados inscritos na base de dados 


\section{REVISTA DE ADMINISTRAÇÃO EDUCACIONAL}

ISSN -2359-1382

\section{dAEPEI}

do IEFP (PORDATA, 2018a). Também nestes concelhos existem 16.009 empresas não financeiras (PORDATA, 2018b) predominantemente, Pequenas e Médias Empresas.

Nestes municípios os setores de atividade económica com mais empresas são o Comércio por grosso e a retalho (3.492), Agricultura, produção animal, floresta e pesca (2.046) e a Indústria transformadora (1.904) (PORDATA, 2018b).

De acordo com dados do Censos 2011, na população abrangida ${ }^{2}$ pelos 5 concelhos, 35 900 pessoas tinham o $1^{\circ}$ ciclo do Ensino Básico, 21859 tinham o $3^{\circ}$ ciclo do Ensino Básico e existiam ainda 13103 analfabetos.

Para ajudar a aumentar a qualificação dos munícipes, tentando corresponder às suas necessidades e do mercado de trabalho, o SFPA disponibiliza educação e formação profissional nas seguintes modalidades:

1. Cursos de Aprendizagem;

2. Cursos de Especialização Tecnológica (CET);

3. Cursos de Educação e Formação de Adultos;

4. Formação Modular Certificada:

\subsection{Vida Ativa Técnicas de Procura de Emprego;}

5. Programa de Formação de Competências Básicas - Formação para a inclusão;

6. Português para Todos;

7. Processos de Reconhecimento, Validação e Certificação de Competências (RVCC).

Entre janeiro de 2017 e maio de 2018, segundo o trabalho de pesquisa que efetuei junto dos técnicos, o SFPA iniciou 648 ações de diferentes modalidades, sendo que a maioria foi de Formação Modular - 134 ações com uma média de 20 formandos cada uma -, e de processos de RVCC - 415 ações individuais.

2 População de 117.974 habitantes na totalidade dos cinco concelhos, segundo o Censos em 2011 (PORDATA, 2015). 


\section{REVISTA DE ADMINISTRAÇÃO EDUCACIONAL}

ISSN -2359-1382

\section{dAEPE|}

Estas ações foram ministradas, maioritariamente, nas áreas de Metalurgia e Metalomecânica, Serralharia e Soldadura. Havendo outras áreas bastante trabalhadas como Saúde, Padaria/Pastelaria, Apoio à Comunidade e Comercial.

\section{Projeto de Estágio}

A Formação Profissional em Portugal, desde 1973, já era considerada algo que habilitaria para o exercício de uma profissão e seria acompanhada de uma educação cultural e científica que promovesse o desenvolvimento da personalidade e a adaptação às exigências sociais e profissionais (PORTUGAL, 1973).

O objetivo da formação profissional deve ser o de preparar para a vida ativa e integrar, de forma dinâmica, os adultos no mundo do trabalho, através da possibilidade de adquirirem conhecimentos e competências profissionais que permitam responder às necessidades de desenvolvimento nacionais e à evolução tecnológica (PORTUGAL, 1986).

Visto que se aprende em todos os contextos da vida quotidiana e que o "saber de experiência feito" deve ser reconhecido, os atuais Centros Qualifica que tem o propósito de levar a cabo os processos de RVCC, fazem ainda mais sentido.

Tendo em conta todo o enquadramento normativo-legal, após alguns meses do início do estágio defini, com aprovação dos orientadores, um Projeto de Estágio a concluir até ao fim do estágio. O objetivo do projeto era, através de variadas atividades, executar diversas funções e deixar um cunho pessoal no SFPA através do melhoramento da divulgação dos processos RVCC.

A estrutura deste Projeto de Estágio apresenta-se em Objetivos Gerais (OG), Objetivos Específicos (OE) e Atividades a desenvolver para alcançar estes objetivos.

\section{OG.1 - Coordenar ações de formação profissional OE.}

1.1 Organizar Dossiês Técnico-Pedagógicos (DTP);

OE. 1.2. Manusear instintivamente a plataforma do Sistema Integrado de Informação e Gestāo da Oferta Educativa e Formativa (SIGO);

OE. 1.3. Planificar ações de formação; 


\section{REVISTA DE ADMINISTRAÇÃO EDUCACIONAL}

ISSN -2359-1382

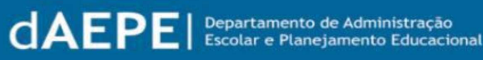

OE. 1.4. Constituir grupos de formação;

OE. 1.5. Acompanhar pedagogicamente os percursos formativos.

\section{Atividades:}

a) Organizar os DTP de acordo com as regras da Agência Nacional para a Qualificação e o Ensino Profissional (ANQEP);

b) Analisar a plataforma SIGO e as suas funcionalidades, assim como o Guia de Utilização;

c) Selecionar formandos da amostra do ficheiro de desempregados a convocar;

d) Abrir e encerrar ações de formação, no local e nas plataformas online;

e) Contactar formadores de forma a obter informações sobre a sua disponibilidade horária e feedback sobre as ações de formação;

f) Elaborar cronogramas;

g) Contratar espaços formativos e formadores para as ações;

h) Garantir equipamentos e consumíveis necessários às ações (quando aplicável);

i) Inserir dados dos formandos no Sistema de Gestão da Formação do IEFP (SGFOR) e associá-los à ação de formação nesta plataforma e no SIGO;

j) Lançar carga horária, pautas de avaliação e assiduidades de formandos no SGFOR;

k) Inserir as classificações finais dos formandos e emitir os respetivos certificados, no SIGO;

1) Contactar empresas para inserção dos formandos em Formação Prática em Contexto de Trabalho (FPCT) ${ }^{3}$;

m) Compor Júris de Certificação.

\section{OG. 2 - Acompanhar o desenvolvimento dos processos de RVCC}

OE. 2.1. Compreender o funcionamento do Centro Qualifica e dos processos de RVCC; OE. 2.2. Participar na etapa de Orientação ao longo da vida;

OE. 2.3. Acompanhar as etapas de reconhecimento, validação e certificação de competências; OE. 2.4. Gerir administrativamente os processos.

\section{Atividades:}

3 Atividades "l” e "m" não foram possíveis de executar visto não ser funcionária do SFPA. 


\section{REVISTA DE ADMINISTRAÇÃO EDUCACIONAL}

ISSN -2359-1382

\section{dAEPEI}

a) Analisar documentos que regulam o funcionamento dos Qualifica e do processo de RVCC;

b) Assistir a reuniões de divulgação dos processos de RVCC com empresas/Instituições

Particulares de Solidariedade Social (IPSS);

c) Preparar e participar nas fases da etapa de Orientação ao longo da vida;

d) Inserir dados dos candidatos e sumários das sessões no SIGO;

e) Gerar documentos necessários para o desenvolvimento do processo de $\mathrm{RVCC}^{4}$;

f) Observar a orientação dos candidatos durante a construção do Portefólio Reflexivo de Aprendizagem (PRA) ${ }^{5}$, segundo os referenciais de competências-chave e profissionais da ANQEP;

g) Ler e explorar os PRA dos candidatos juntamente com os mesmos;

h) Monitorizar o reconhecimento de competências;

i) Presenciar júris de Certificação;

j) Assistir à avaliação e validação das competências dos formandos.

\section{OG. 3 - Inovar na divulgação dos processos de}

RVCC OE. 3.1. Criar uma base de dados de empresas e

IPSS; OE. 3.2. Divulgar o processo de RVCC.

\section{Atividades:}

a) Criar uma base de dados com empresas e IPSS do concelho de Águeda com vários dados importantes.

b) Propor e efetuar a divulgação do processo de RVCC através das redes sociais e do e-mail marketing.

\section{O estágio}

Em julho de 2017 dirigi-me ao SFPA para saber se haveria possibilidade de realizar

4 Documentos gerados no SIGO. Atividade não possível de executar assim como a atividade " $h$ ".

5 Documento pessoal, usado como instrumento base do processo de RVCC, que integra componentes reflexivas e críticas associadas a evidências e relatos pessoais (AMADO \& FERREIRA, 2014), considerado por Bogdan \& Biklen "qualquer narrativa feita na primeira pessoa que descreva as ações, experiências e crenças dos indivíduos (...) autoreveladora da visão que a pessoa tem das suas experiências” (1994, p. 275). 


\section{REVISTA DE ADMINISTRAÇÃO EDUCACIONAL}

ISSN -2359-1382

\section{dAEPEI}

estágio curricular. Depois da aprovação formal, iniciei o estágio em setembro de 2017 e ao longo do mesmo fui acompanhada por 2 professores Doutores responsáveis pela orientação do meu estágio, na FPCEUC e pelo orientador local, Diretor Adjunto do SFPA.

Desenvolvi funções relacionadas com a coordenação de ações de formação profissional, acompanhamento dos processos de RVCC e inovação na divulgação dos mesmos. Antes de iniciar "autonomamente" as tarefas, acompanhei (sensivelmente durante um mês e meio) as Técnicas do SFPA na realização das suas tarefas.

\section{Coordenação de ações de formação profissional}

Para coordenar ações de formação é necessário conhecer todas as medidas de educação e formação existentes, sendo obrigatória a leitura da legislação e dos guias organizativos que as regulamentam e organizam.

Desta função fazia parte a organização de DTP, que se baseiam numa estrutura predefinida pela ANQEP. É necessário obter todos os documentos que o constituem, elaborar lombadas, índices e separadores e organizar toda a documentação. Elaborei na totalidade, 2 DTP completamente diferentes, que se tornaram "arquivos técnico-pedagógicos". Um, de uma ação de formação, contou com 4 dossiês e outro, do Centro Qualifica, contou com 26 dossiês, nem todos eles completos com os documentos necessários.

Além de elaborar de raiz estes arquivos, também organizei DTP de ações já existentes. Relativamente a estes DTP, elaborei uma folha de identificação de formandos, onde se podia colocar o nome e a foto dos mesmos, tornando mais fácil reconhecer os membros de cada turma.

Para além disto também é necessário manusear instintivamente o SIGO. Este sistema permite gerir a formação profissional que cada pessoa frequenta e a posterior emissão de certificados que comprovam a sua frequência e aprovação.

O IEFP utiliza muitas outras plataformas como o Sistema de Informação e de Gestão da área do Emprego (SIGAE) e o SGFOR, com os quais também trabalhei. Nestas plataformas inseri dados de formandos, encaminhei-os para a frequência de ações de formação, iniciei e encerrei ações de formação e emiti certificados. 


\section{REVISTA DE ADMINISTRAÇÃO EDUCACIONAL}

ISSN -2359-1382

\section{dAEPE|}

Devido ao facto de a planificação ser imprescindível para o arranque das ações de formação, tive a oportunidade de planificar e acompanhar 7 ações (cf. Tabela 1).

Tabela 1 - Ações planificadas e acompanhadas no estágio

\begin{tabular}{|c|c|c|c|c|c|}
\hline Modalidade & $\begin{array}{c}\text { Saída } \\
\text { profissional }\end{array}$ & Nível & Tarefa & Início da ação & $\begin{array}{c}\text { Fima da } \\
\text { ação }\end{array}$ \\
\hline APZ & $\begin{array}{l}\text { Técnico/a } \\
\text { comercial } \\
1^{\circ} \text { ano }\end{array}$ & 4 & Planificação & $\begin{array}{l}\text { Não iniciou por } \\
\text { indisponibilidade }\end{array}$ & \\
\hline APZ & $\begin{array}{l}\text { Técnico } \\
\text { Auxiliar de } \\
\text { Saúde (TAS)- } \\
1^{\circ} \text { ano }\end{array}$ & 4 & $\begin{array}{l}\text { Acompanhamento- } \\
1 \text { mês }\end{array}$ & $12 / 9 / 2017$ & $9 / 4 / 2018$ \\
\hline APZ & TAS- $2^{\circ}$ ano & 4 & Planificação & $2 / 5 / 2018$ & $6 / 2 / 2019$ \\
\hline $\begin{array}{l}\text { FM- Ativos } \\
\text { Empregados }\end{array}$ & $\begin{array}{l}\text { Espanhol } \\
\text { Iniciação }\end{array}$ & 4 & Planificação & $23 / 5 / 2018$ & $26 / 6 / 2018$ \\
\hline $\begin{array}{l}\text { FM- Ativos } \\
\text { empregados }\end{array}$ & $\begin{array}{l}\text { Espanhol } \\
\text { continuação }\end{array}$ & 4 & Planificação & $2 / 7 / 2018$ & $30 / 7 / 2018$ \\
\hline $\begin{array}{l}\text { Vida Ativa- } \\
\text { qualifica }\end{array}$ & $\begin{array}{l}\text { Cuidados } \\
\text { humanos } \\
\text { básicos- } \\
\text { alimentação e } \\
\text { saúde }\end{array}$ & 2 & Planificação & $28 / 5 / 2018$ & $7 / 9 / 2018$ \\
\hline EFA & $\begin{array}{l}\text { Padeiro a- } \\
\text { Pasteleiro a }\end{array}$ & 3 & $\begin{array}{l}\text { Planificação e } \\
\text { acompanhamento }\end{array}$ & $24 / 1 / 2018$ & $11 / 4 / 2019$ \\
\hline EFA & TAS & 4 & $\begin{array}{l}\text { Planificação e } \\
\text { acompanhamento }\end{array}$ & $14 / 5 / 2018$ & $25 / 9 / 2019$ \\
\hline EFA & TAS & 4 & $\begin{array}{l}\text { Acompanhamento } \\
2 \text { meses }\end{array}$ & $23 / 1 / 2017$ & $8 / 5 / 2018$ \\
\hline EFA & TAS & PRO & $\begin{array}{l}\text { Acompanhamento } \\
2 \text { meses }\end{array}$ & $13 / 11 / 2017$ & $8 / 11 / 2019$ \\
\hline EFA & $\begin{array}{l}\text { Técnico/a de } \\
\text { Cozinha e } \\
\text { Pastelaria }\end{array}$ & 4 & $\begin{array}{l}\text { Acompanhamento } \\
2 \text { meses }\end{array}$ & $18 / 9 / 2017$ & $28 / 1 / 2019$ \\
\hline EFA & $\begin{array}{l}\text { Técnico/a de } \\
\text { Geriatria }\end{array}$ & 4 & $\begin{array}{l}\text { Acompanhamento } \\
2 \text { meses }\end{array}$ & $10 / 7 / 2017$ & $9 / 11 / 2018$ \\
\hline
\end{tabular}

Fonte: O autor (2018) 


\section{REVISTA DE ADMINISTRAÇÃO EDUCACIONAL}

ISSN -2359-1382

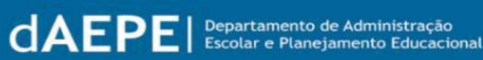

A planificação destas ações era feita geralmente com 1 a 2 meses de antecedência, pois dependia de fatores como a disponibilidade dos formadores e das instalações. O IEFP tem documentos e procedimentos bastante normalizados, e assim a planificação consistia em preencher esses documentos, elaborando o cronograma da ação - às vezes para um ano completo de formação - de acordo com a disponibilidade dos formadores.

Escolhia, de acordo com o Catálogo Nacional de Qualificações, as Unidades de Formação de Curta Duração (UFCD) que iriam compor o plano curricular das ações; enviava o cronograma definido, para todos os formadores, aguardando a sua aprovação e fazendo alterações caso fossem necessárias; inseria no SGFOR todos os dados da ação; elaborava os contratos dos Formadores com informações como honorários e horas a lecionar e sempre que aplicável, os Contratos de Espaços Externos. Esta era uma tarefa morosa, pois tinha que contactar vários formadores e "jogar" com todas as suas disponibilidades, as cargas horárias das UFCD, a ordem de lecionação das mesmas e as interrupções letivas.

Depois de planificada a ação, era necessário constituir grupos de formação. Para isto precisava de, sensivelmente, 1 mês antes da ação iniciar, aceder ao SIGAE - tarefa da Técnica responsável pela constituição do grupo, que eu apenas pude ver fazer -, escolher as características que os formandos devem ter (idade, habilitações, situação face ao emprego) para emissão de uma lista com os ID (número de utente) das pessoas inscritas no Serviço de Emprego de Águeda que congregam as características pedidas.

A partir desta listagem, todos eram convocados por carta, a comparecer, geralmente no SFPA, para uma sessão coletiva onde lhes era explicado o motivo da convocatória, a forma como funcionaria a ação e os apoios que podem receber, e lhes são pedidos alguns documentos que devem trazer no $1^{\circ}$ dia de formação. Nestas sessões pude participar, explicando aos candidatos os apoios financeiros e ajudando-os a preencher os formulários de inscrição. Todos os candidatos convocados, que recebam algum apoio da Segurança Social por se encontrarem na situação de desempregados são obrigados a participar até encontrarem um emprego ou apenas poderão faltar com justificação médica. Posteriormente, os inscritos eram novamente convocados, para uma entrevista de seleção individual com a psicóloga do SFPA. 


\section{REVISTA DE ADMINISTRAÇÃO EDUCACIONAL}

ISSN -2359-1382

\section{dAEPE|}

Quando iniciadas as ações pude acompanhar pedagogicamente os percursos

formativos indo às sessões de acolhimento dos formandos onde os ajudava a preencher as fichas de identificação, distribuía material escolar, explicava os apoios sociais que poderiam receber e recolhia os documentos necessários à inscrição na ação. Posteriormente, fazia um levantamento no SIGO dos candidatos que já constavam do sistema e que já tinham o Passaporte Qualifica ${ }^{6}$ para verificar quais as UFCD que já tinham validado, para que não fossem obrigados a frequentá-las de novo. Preparava o dossiê de sala ${ }^{7}$ da ação e associava, no SIGO, os formandos à ação. Todas as ações tinham mensalmente reuniões da equipa técnicopedagógica, sendo que pude participar numa destas reuniões, onde se emitia e recolhia feedback sobre a evolução dos formandos. Também mensalmente era necessário emitir a carga horária das ações e as assiduidades dos formandos no SGFOR, imprimir os mapas de assiduidade emitidos por esta plataforma e fazê-los chegar á Técnica de Serviço Social responsável pela ação, bem como imprimir as folhas de sumário/de presenças para dar ao mediador da ação. Ao longo das ações também era necessário acompanhar e registar as permutas de aulas que existiam entre os formadores e que eram comunicadas via e-mail e após registá-las no cronograma da ação, confirmar a troca efetuada e enviar o cronograma para o mediador da ação. Estas tarefas foram desenvolvidas por mim em 5 ações, durante 2 meses.

Para todas as ações que tinham FPCT era necessário garantir um local de estágio e contactar entidades. Este contacto só podia ser efetuado por Técnicas do SFPA, contudo, para 4 ações elaborei um documento onde constavam os nomes dos formandos, número de identificação civil, nome e morada da entidade, pessoa a contactar, contacto e NIF. Também nesta etapa pude, numa das ações que acompanhei, associar no SGFOR, os formandos às instituições acolhedoras da FPCT.

\section{Acompanhamento dos processos de RVCC}

6 Instrumento tecnológico de registo das qualificações e competências adquiridas ou desenvolvidas ao longo da vida do adulto e de orientação para percursos de aprendizagem, que simula diversos percursos de qualificação possíveis para a obtenção de novas qualificações e/ou progressão escolar e profissional (DGEE \& ANQEP, 2017).

7 Dossiê que contém o Referencial de Formação, folhas de sumários/de presenças, lista de formandos, folha com UFCD, carga horária e respetivo formador responsável, e cronograma da ação. 


\section{REVISTA DE ADMINISTRAÇÃO EDUCACIONAL}

ISSN -2359-1382

\section{dAEPE|}

Como no Centro Qualifica do SFPA, se desenvolvem processos de RVCC, que considero serem de extrema importância para a qualificação da população portuguesa, pedi para acompanhar estes processos.

Não consegui acompanhar um processo de RVCC do início ao fim, pois têm uma duração extensa, podendo demorar 6 meses ou mais de 1 ano. No entanto, pude acompanhar vários processos, individuais, em grupo, em IPSS e empresas, nos vários concelhos abrangidos pelo SFPA, em áreas distintas e em todas as fases pelas quais devem passar até se concluírem.

Para poder atingir este objetivo foi fundamental compreender o funcionamento dos Centros Qualifica e dos processos de RVCC. Apesar de não serem processos de formação, não podendo ser incluídos pelas entidades empregadoras nas 35 horas obrigatórias de formação contínua mínima, são uma mais valia para as mesmas pois o RVCC permite o aumento de mão de obra qualificada e a atualização de conhecimentos dos trabalhadores, e para os candidatos pois veem reconhecidas as suas competências e experiência profissional formalmente e podem aumentar o seu nível de escolaridade.

$\mathrm{Na}$ etapa de Orientação ao longo da vida, quando as pessoas se dirigiam ao SFPA para demonstrar interesse em frequentar estes processos, as Técnicas de Orientação, Reconhecimento, Validação e Certificação de Competências (TORVCC) marcavam uma reunião com o objetivo de esclarecer o modo de funcionamento do RVCC. Pude participar em várias e explicar o desenvolvimento dos processos. Nestas sessões de acolhimento era feita uma auscultação das certificações e áreas pretendidas. Entreguei aos candidatos vários documentos explicativos, sobre o Centros Qualifica e o RVCC; esquemas síntese dos referenciais dos níveis de escolaridade e de algumas saídas profissionais que podem ser trabalhadas com os temas a abordar; fichas de inscrição e fichas de diagnóstico iniciais.

Os candidatos recebiam ainda uma pasta com folhas de apontamentos e uma ficha de diagnóstico inicial sobre competências, interesses, motivações e dados pessoais, para facilitarem o diagnóstico de necessidades feito pelas TORVCC. No âmbito destas sessões pude ainda participar esclarecendo dúvidas dos candidatos sobre o RVCC e sobre o preenchimento das fichas, entregando as pastas e recebendo os documentos pedidos certificado de habilitações e as fichas preenchidas. 


\section{REVISTA DE ADMINISTRAÇÃO EDUCACIONAL}

ISSN -2359-1382

\section{dAEPE|}

$\mathrm{Na}$ segunda sessão, de Diagnóstico, Informação e Orientação, entregava aos candidatos o Código do Passaporte Qualifica, sendo explicada pela TORVCC a forma de aceder ao Passaporte, um documento orientador da narrativa autobiográfica, uma cópia do Plano Individual de Carreira, do Plano Individual de Encaminhamento e do Contrato de Formação Profissional. No documento orientador estava explicada a estrutura base do PRA e como nele devia ser desenvolvida a história de vida de cada candidato. Nesta sessão eram preenchidas atividades de diagnóstico por aqueles que pretendiam certificação escolar ou dupla (escolar e profissional), para identificar as suas competências. Verificados os instrumentos de diagnóstico inicial, a TORVCC orienta-os para a certificação mais adequada. Quando o percurso é escolhido, o candidato é encaminhado para o mesmo, ficando formalizado num Contrato que leva ao processo de Encaminhamento.

Posteriormente a estas sessões, pude acompanhar pormenorizadamente as etapas de reconhecimento, validação e certificação de competências. Na etapa de reconhecimento e validação de competências, a TORVCC explicava como iria ser desenvolvido o PRA de acordo com várias fases da vida e a forma como as competências eram trabalhadas e reconhecidas era muito ligada ao quotidiano dos candidatos.

Ao longo das sessões desta etapa, a TORVCC orientava os candidatos no desenvolvimento do PRA, de modo a evidenciarem as competências necessárias para o reconhecimento e validação do referencial que estavam a trabalhar - tarefa que desenvolvi com alguns candidatos.

Quando os candidatos terminavam as tarefas pedidas enviavam o PRA para a TORVCC por e-mail, esta corrigia indicando o que deviam alterar, monitorizava as competências evidenciadas através de uma Grelha e reenviava o PRA para os candidatos. Nesta etapa pude ler passagens de alguns PRA e tirar dúvidas aos candidatos sobre as tarefas pedidas.

Relativamente à etapa de formação complementar, nas áreas em que os candidatos não tinham conseguido evidenciar competências no PRA, apenas pude assistir a uma aula na área Comercial, pois foi a única compatível com a minha disponibilidade horária. Nestas sessões eram desenvolvidas e corrigidas tarefas que, eram anexadas ao PRA, e que permitiam aos candidatos evidenciar competências nos temas necessários e/ou nas tarefas que um 


\section{REVISTA DE ADMINISTRAÇÃO EDUCACIONAL}

ISSN -2359-1382

\section{dAEPEI}

profissional de determinada área deve saber fazer de acordo com os referenciais profissionais da ANQEP.

Com a finalização da formação e do desenvolvimento do PRA, a equipa técnicopedagógica preparava a sessão de Júri de Certificação de Competências. Os formadores compunham a Prova de Aptidão Final com os elementos, questões e cotações que consideravam pertinentes, adaptando-a a cada candidato. Participei na preparação de 2 provas - de Técnico Comercial e Agente em Geriatria - onde ajudei a distribuir as cotações pelas questões e a recortar material de apoio. Por fim, os candidatos eram levados á sessão de Júri, algumas das quais também assisti. Antes de irem á sessão de Júri, era necessário inserir no SIGO, a avaliação final de alguns formandos, tarefa que também fiz.

Todas as etapas mencionadas são geridas no SIGO, devendo ficar registadas todas as sessões executadas. Para isto é necessário gerir administrativamente os processos de RVCC.

\section{Inovação na divulgação dos processos de RVCC}

Relativamente aos processos de RVCC e após 7 meses confrontada com a realidade vivida no Centro Qualifica do SFPA, decidi desenvolver algo inovador na divulgação dos mesmos. Geralmente, quem conhece o RVCC é através do "passa a palavra" e eu ambicionava dá-lo a conhecer ao maior número de pessoas e entidades possível, do concelho de Águeda.

Inicialmente criei uma base de dados de empresas e IPSS do concelho e tinha como objetivo deixar às TORVCC uma ferramenta útil para sempre que quisessem divulgar o Centro Qualifica e os processos de RVCC. Esta base serviria também para fazer e-mail marketing através dos contatos conseguidos.

A base de dados, feita no Access, teria uma folha para Empresas e outra para IPSS e cada uma continha nome, morada, Classificação de Atividades Económicas (CAE), e-mail, contacto e número de trabalhadores. Para construir esta base de dados recorri a sites como o Gescontact (2018), o Racius (2018) e o Universia (2016) e a uma revista do Diário de Aveiro (2016).

Como os Técnicos tinham que contactar empresas para garantir locais de estágio, 


\section{REVISTA DE ADMINISTRAÇÃO EDUCACIONAL}

ISSN -2359-1382

\section{dAEPE|}

decidi incluir folhas para outros concelhos que já tivessem colaborado com o SFPA. Para elaborar estas folhas, "Empresas Outros Concelhos" e "IPSS Outros Concelhos", onde constavam para além dos dados já referidos, o concelho ao qual pertenciam, consultei dossiês e tabelas de dados disponibilizados por alguns Técnicos.

Esta base de dados totalizou 44 IPSS e 974 Empresas, e ficou disponibilizada na rede interna do SFPA. Nela há a possibilidade de se pesquisar a entidade pretendida através do nome ou selecionando o concelho/CAE/contato/e-mail pretendido ou adicionar novas entidades.

No que diz respeito à divulgação dos processos de RVCC, procedi ao e-mail marketing. Enviei para 225 empresas e 37 IPSS do concelho ${ }^{8}$, um e-mail (vd. Figura 3) que incluía um link para um vídeo e outro para um Questionário para empresas do concelho de Águeda ${ }^{9}$.

Figura 3 - E-mail Marketing

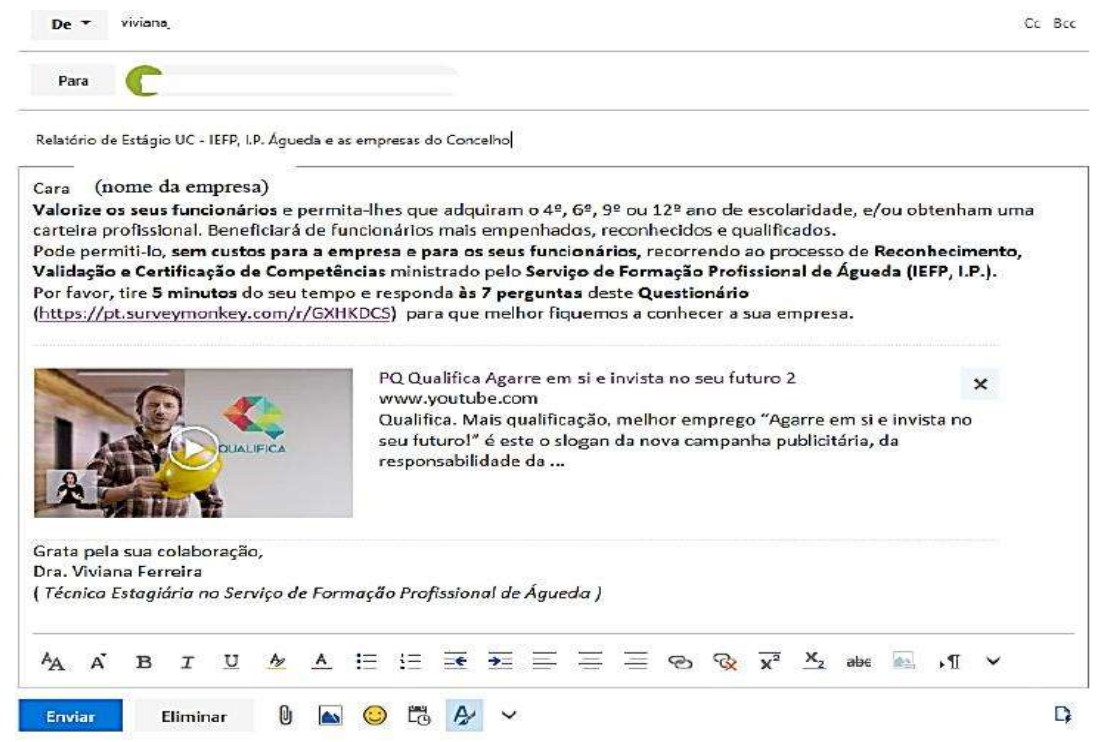

O questionário foi elaborado no SurveyMonkey, disponibilizava 7 questões e pretendia conhecer melhor as entidades e saber qual a sua relação com os processos de RVCC, ao mesmo tempo que permitia a sua divulgação. O feedback recebido foi apenas de 12 entidades

8 Número de e-mails enviado limitado ao tempo de estágio.

9 Disponível para consulta em https://pt.surveymonkey.com/r/GXHKDCS?

fbclid=IwAR2o6sFEQXtLuMFepa91eZAbCM0m-3kPUpvdSZQOuvNxu46qMOEHmlbrVsQ

Revista Administração Educacional - CE - UFPE Recife-PE, V.11 N. 1 p. 159-180, jan./jun. 2020 


\section{REVISTA DE ADMINISTRAÇÃO EDUCACIONAL}

ISSN -2359-1382

\section{dAEPEI}

sendo que, algumas demonstraram interesse em receber uma sessão de esclarecimento sobre o RVCC, deixando o seu contacto. A meu ver este baixo número deveu-se ao facto de não ter podido usar um e-mail institucional do IEFP ou colocado os contatos do SFPA, perdendo alguma credibilidade; devido ao facto da maioria das pessoas não gostar de preencher questionários e de algumas empresas preferirem ter colaboradores com baixas qualificações, pois um colaborador informado é mais exigente.

Para que esta divulgação fosse mais abrangente, utilizei as redes sociais. Divulguei os processos de RVCC no Facebook do CEFPA. Visto que não era administradora da página, recorri ao responsável pelas publicações e fizemos uma publicação que contou, até 30 de junho de 2018, com 1070 visualizações.

\section{Outras atividades}

Além das atividades descritas, pude realizar atividades "não previstas" por mim, tais como:

a) Elaboração de mapas de ocupação, de cada formador interno onde consta a sua ocupação horária para os anos de 2019-2021, de acordo com feriados e interrupções letivas.

b) Inserção de interrupções letivas no SGFOR para organização das cargas horárias relativas a todas as ações de formação que lá fossem inseridas.

c) Verificação das horas ministradas pelos formadores em 2016, através de uma tabela e da declaração de rendimentos.

d) Representação do SFPA, juntamente com algumas Técnicas do CEFPA, na $\mathbf{2}^{\mathbf{a}}$ Feira do Emprego e do Empreendedorismo de Águeda em setembro de 2017 na Fundação Dionísio Pinheiro e Alice Cardoso Pinheiro.

e) Participação como formanda, num projeto piloto de formação à distância sobre a UFCD 8600 - Competências empreendedoras e técnicas de procura de emprego.

f) Organização do Plano de Formação Modular de 2018, através da ordenação por área de formação, número da UFCD, designação da mesma, carga horária, nível de formação e número de formandos.

g) Reformulação da Ficha de Inscrição da Formação Modular, com o objetivo de reduzir o tamanho da mesma tornando-se mais sustentável a sua impressão e o seu 


\section{REVISTA DE ADMINISTRAÇÃO EDUCACIONAL}

ISSN -2359-1382

\section{dAEPEI}

preenchimento. A ficha original era extensa levando os candidatos desta modalidade a não a preencherem na totalidade. Assim criei uma ficha de 2 páginas - inicialmente com 3 páginas - de preenchimento online com exemplos de preenchimento em alguns campos e uma ficha de preenchimento manual com estrutura igual, sem exemplos.

h) Colaboração na preparação de uma ação de Português Para Todos, na qual inseri os dados dos formandos estrangeiros no SGFOR e os encaminhei, na mesma plataforma, para a ação.

i) Preenchimento de formulários de candidatura do SFPA a 2 CET para 2019. Para cada candidatura preenchi vários documentos, que organizei por pastas, para que, posteriormente, algum Técnico pudesse continuar o trabalho por mim desenvolvido e proceder à candidatura.

j) Elaboração de cartões de identificação de formandos. Esta tarefa consistiu em elaborar, recortar e plastificar os respetivos cartões.

k) Passagem pela oficina de formação em soldadura do SFPA, a título de curiosidade pessoal, para conhecer os tipos de soldadura desenvolvidos na mesma.

No último dia de estágio terminei e disponibilizei a base de dados que me propus fazer, na rede partilhada. Fiz a divulgação do processo de RVCC na página de Facebook do CEFPA, ajudei no transporte e acompanhamento de jovens do $9^{\circ}$ ano de uma escola local ao SFPA e despedi-me de toda a equipa com um bolo feito por mim.

\section{Conclusão}

Citando Hargreaves (2003, p. 101) “o ensino deve ser uma carreira de primeira eleição, uma tarefa para adultos maduros, um compromisso a longo prazo, uma missão social e um emprego para a vida" . Revendo-me nesta citação, posso afirmar que aprendi imenso neste estágio, pois tive a oportunidade de enriquecer pessoal e profissionalmente. Desenvolvi competências de Excel, SIGO, SGFOR, comunicação interpessoal, relações sociais e laborais, trabalho em equipa, entre muitas outras, úteis ao trabalho na área da Organização e Gestão da Formação.

As atividades nas quais estive permitiram a compreensão de todos os procedimentos necessários à administração, planificação e acompanhamento de ações de formação e ao 


\section{REVISTA DE ADMINISTRAÇÃO EDUCACIONAL}

ISSN -2359-1382

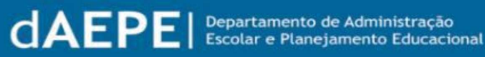

desenvolvimento dos processos de RVCC. Pude acompanhar e participar em vários procedimentos e fases, interagindo com profissionais de vastas áreas e candidatos de diferentes idades e condições socioeconômicas.

A maioria das atividades desenvolvidas foi ao encontro das definidas, previamente, no Projeto de Estágio, levando à concretização de todos os objetivos. No entanto, o facto do SFPA pertencer ao IEFP delimitou a minha atuação como estagiária.

Relativamente ao papel que um profissional em Gestão da Formação e Administração Educacional pode desenvolver neste tipo de entidade e tendo em conta a formação académica que vai recebendo ao longo do tempo, pude constatar que faz todo o sentido devido à familiarização com o vocabulário técnico usado e com as medidas de educação e formação desenvolvidas. Estes são aspectos fundamentais para a organização, gestão, coordenação e orientação pedagógicas dos percursos formativos.

Ao longo da minha formação académica adquiri conhecimentos e competências de administração, planificação, desenvolvimento, acompanhamento e avaliação de percursos formativos, que pude colocar em prática e que se tornaram, sem dúvida, numa mais valia para o desenvolvimento do estágio.

\section{Referências}

AMADO, J. \& FERREIRA, S. Documentos pessoais (e não pessoais). In: AMADO, J. (Coord.). Manual de Investigação Qualitativa em Educação. $2^{\text {a }}$ Ed. Coimbra: Imprensa da Universidade de Coimbra, 2014, p. 275-28.

BOGDAN, R. \& BIKLEN, S. Investigação qualitativa em educação. Porto: Porto Editora, 1994, $336 \mathrm{p}$.

CENTRO DE EMPREGO E FORMAÇÃO PROFISSIONAL DE ÁGUEDA. Plano de actividades de 2013. Águeda: CEFPA, 2013.

DIÁRIO DE AVEIRO (2016). 1.500 maiores empresas Aveiro 2016. Aveiro: Diário de Aveiro.

DIREÇÃO GERAL DE ESTATÍSTICAS DA EDUCAÇÃO \& AGÊNCIA NACIONAL PARA A QUALIFICAÇÃO E O ENSINO PROFISSIONAL. Portal Qualifica. 2017. Disponível em: $\leq$ https://www.qualifica.gov.pt/\#/>. Acesso em: 12 fev. 2018 


\section{REVISTA DE ADMINISTRAÇÃO EDUCACIONAL}

ISSN -2359-1382

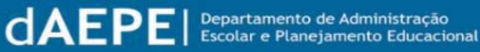

FACULDADE DE PSICOLOGIA E DE CIÊNCIAS DA EDUCAÇÃO DA UNIVERSIDADE DE COIMBRA (FPCEUC). Regulamento do Mestrado em Gestão da Formação e Administração Educacional. Coimbra: FPCEUC, 2015. Disponível em: $<$ https://www.uc.pt/regulamentos/uo/uei/fpce/vigentes/regulamento mestrado_gestao formac ao administracao educacional FPCEUC>. Acesso em: 12 fev. 2018

Regulamento dos estágios no âmbito dos Mestrados Académicos - área das

Ciências da Educação. Coimbra: FPCEUC, 2016. Disponível em: $\leq$ https://www.uc.pt/regulamentos/uo/uei/fpce/vigentes/regulamento_estagios ambito mestrad os academicos area ciencias_educacao $>$. Acesso em: 12 fev. 2018

GESCONTACT EMPRESAS. Empresas do concelho de Águeda. 2018. Disponível em: $<$ https://www.gescontact.pt/distrito/aveiro/concelho/agueda>. Acesso em: 25 abr. 2018

GOOGLE MAPS. Rua Dr. Barbas dos Anjos - Águeda, Aveiro. 2017. Disponível em: $\leq$ https://www.google.com/maps/@40.5920531,-8.4544655,3a,75y,265.01h,89.72t/data=!3m6!1e1!3m4!1sZ1KH8x0b9AH5ZEJFYDb iw!2e0 ! 7i13312!8i6656>. Acesso em: 25 abr. 2018

INSTITUTO DO EMPREGO E FORMAÇÃO PROFISSIONAL. História do IEFP. 2017. Disponível em: $\leq$ https://www.iefp.pt/historia $>$. Acesso em: 25 abr. 2018

Centros Qualifica - guia organizativo para a rede de centros do IEFP, I.P. Lisboa: IEFP, 2018

PORDATA. Municípios - População residente com 15 e mais anos segundo os Censos: total e por nível de escolaridade completo mais elevado. 2015. Disponível em: $\leq$ http://www.pordata.pt/Municipios/Popula $\% \mathrm{C} 3 \% \mathrm{~A} 7 \% \mathrm{C} 3 \% \mathrm{~A} 3 \mathrm{o}+$ residente + com $+15+\mathrm{e}+$ mais + anos + segundo + os + Censos + total $+\mathrm{e}+$ por $+\mathrm{n} \% \mathrm{C} 3 \% \mathrm{ADvel}+\mathrm{de}+$ escolaridade + completo + mais + elevado-69>. Acesso em: 28 abr. 2018

Municípios - população residente. 2018. Disponível em: $<$ https://www.pordata.pt/Municipios/Popula\%C3\%A7\%C3\%A3o+residente-359>. Acesso em: 28 abr. 2018

Municípios - desempregados inscritos nos centros de emprego e de formação profissional. 2018a. Disponível em: $\leq$ https://www.pordata.pt/Municipios/Desempregados + inscritos + nos + centros + de + emprego + e + de+forma $\% \mathrm{C} 3 \% \mathrm{~A} 7 \% \mathrm{C} 3 \% \mathrm{~A} 3 \mathrm{o}+$ profissional-220>. Acesso em: 28 abr. 2018

Municípios - empresas não financeiras: total e por setor de atividade económica. 2018b. Disponível em: $\quad \leq$ https://www.pordata.pt/Municipios/Empresas $+\mathrm{n}$ $\% \mathrm{C} 3 \% \mathrm{~A} 3 \mathrm{o}+$ financeiras + total $+\mathrm{e}+$ por + sector $\quad+$ de + actividade + econ $\% \mathrm{C} 3 \% \mathrm{~B} 3 \mathrm{mica}-346>$. Acesso em: 28 abr. 2018 


\section{REVISTA DE ADMINISTRAÇÃO EDUCACIONAL}

ISSN -2359-1382

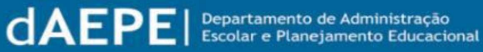

PORTUGAL IN OUT. Distrito de Aveiro. 2016. Disponível em: $\leq \mathrm{http}$ ://www.portugalinout.com/distrito-de-aveiro/>. Acesso em: 28 abr. 2018

PORTUGAL. Lei N. ${ }^{\circ}$ 5, de 25 de julho de 1973. Aprova as bases a que deve obedecer a reforma do sistema educativo. Lisboa: Presidência da República, julho de 1973. Disponível em: $\leq$ http://193.137.22.223/fotos/editor2/1973.pdf >. Acesso em: 29 abr. 2018

Lei N. ${ }^{0}$ 7, de 12 de fevereiro de 2009. Aprova a revisão do Código do Trabalho. Lisboa: Assembleia da República, fevereiro de 2009. Disponível em: $\leq$ https://dre.pt/application/file/a/602193>. Acesso em: 29 abr. 2018

Lei N. ${ }^{\circ}$ 46, de 14 de outubro de 1986. Lei de Bases do Sistema Educativo. Lisboa: Assembleia da República, outubro de 1986.

Decreto-Lei N. ${ }^{\circ}$ 143/2012, de 11 de julho de 2012. Aprova a orgânica do Instituto do Emprego e Formação Profissional, I. P. Lisboa: Ministério da Economia e do Emprego, julho de 2012. Disponível em: $\leq$ https://dre.pt/application/file/a/179641>. Acesso em: 29 abr. 2018

Decreto-Lei N. ${ }^{\circ}$ 519-A2/79, de 29 de dezembro de 1979. Considera atribuições do Ministério do Trabalho, além das referidas no artigo 2..$^{\circ}$ do Decreto-Lei n. ${ }^{\circ}$ 47/78, de 21 de Março, participar activamente na concepção da política global de emprego. Lisboa: Ministério do Trabalho, dezembro de 1979. Disponível em: $\leq$ https://dre.pt/application/file/a/157106>. Acesso em: 29 abr. 2018

Portaria N. ${ }^{\mathbf{0}}$ 319/2012, de 12 de outubro de 2012. Aprova os estatutos do Instituto do Emprego e da Formação Profissional, I. P. Lisboa: Ministérios das Finanças e da Economia e do Emprego, outubro de 2012. Disponível em: $\leq$ https://dre.pt/application/dir/pdf1sdip/2012/10/19800/0584505858.pdf $>$. Acesso em: 29 abr. 2018

RACIUS. Empresas em Águeda em atividade. 2018. Disponível em: $<$ https://www.racius.com/empresas-em-portugal/agueda/em-atividade/ $>$. Acesso em: 05 mar. 2018

UNIVERSIA PORTUGAL. Lista de empresas em União das freguesias de Águeda e Borralha. 2016. Disponível em: $\leq$ https://guiaempresas.universia.pt/freguesia/UNIAOFREGUESIAS-AGUEDABORRALHA/?qPagina=15>. Acesso em: 05 mar. 2018

VISITAR PORTUGAL. Águeda concelho. 2017. Disponível em: $\leq$ https://www.visitarportugal.pt/distritos/d-aveiro/c-agueda>.Acesso em: 05 mar. 2018 